\title{
DESEMPENHO PRODUTIVO DA CULTURA DA SOJA EM RAZÃO DA APLICAÇÃO ÁCIDO HÚMICO E FÚLVICO NA SEMEADURA E VIA FOLIAR
}

Tiago Aranda Catuchi, Vinicius José Souza Peres, Fernando Vinicius Bressan, Elton Anderson Aranda, Alexandre Paião Leite da Silva.

Universidade do Oeste Paulista - UNOESTE, Mestrando em Agronomia, Presidente Prudente, SP. E-mail: tiago@unoeste.br.

\section{RESUMO}

O trabalho teve o objetivo de avaliar o desempenho da cultura da soja com aplicação de ácidos fúlvicos e húmicos no sulco de semeadura e via foliar juntamente com herbicidas. Foi realizada a condução de dois experimentos, em ambos adotou-se o delineamento experimental em faixas, com quatro repetições. No experimento 1 e 2 foi realizado a aplicação de ácido húmico e ácido fúlvico, respectivamente. No experimento 1 , os tratamentos foram constituídos pelas seguintes formase doses de aplicação de ácido húmico: Testemunha (sem aplicação de produto); T1: aplicação $380 \mathrm{~g}$ ha-1 de ácido húmico via solo; T2; T3; T4: aplicação de ácido húmico via foliar nas doses de $380 ; 760 ; 1.520 \mathrm{~g} \mathrm{~L}$ ha-1, respectivamente. No experimento 2 , os tratamentos foram constituídos pelas seguintes formas e doses de aplicação de ácido fúlvico: Testemunha (sem aplicação de produto); T1: aplicação $200 \mathrm{~g}$ ha-1 de ácido húmico via solo; T2; T3; T4: aplicação de ácido húmico via foliar nas doses de 200; 400; 800 g L ha-1. A aplicação de ácido húmico no sulco de semeadura e via foliar na dose de $380 \mathrm{~g}$ ha-1 no estádio V4 da soja, e a aplicação de ácido fúlvico no sulco de semeadura promoveu aumento do crescimento vegetativo das plantas.Em geral a aplicação de ácido húmico ou ácido fúlvico no sulco de semeadura e via foliar no estádio V4 com a dose de $380 \mathrm{~g}$ ha-1 ou $200 \mathrm{~g}$ ha-1, respectivamente para ácido húmico e fúlvico, aumentou do número de vagens por planta, repercutindo no aumento de produtividade de grãos.

Palavras-Chaves: Soja, Matéria Orgânica, Ácido Húmico, Ácido Fúlvicos, foliar

\section{PRODUCTIVE PERFORMANCE OF SOYBEAN CROP BY REASON OF APPLICATION HUMIC ACID AND FULVIC THE SEEDING AND ROUTE LEAF}

\begin{abstract}
The study aimed to evaluate the soybean performance with application of fulvic and humic acids in the seed furrows and foliar with herbicides. Driving was carried out two experiments, both adopted the experimental design of tracks, with four replications. In experiment 1 and 2 was performed applying humic acid and fulvic acid, respectively. In experiment 1 , the treatments were the following forms and humic acid application rates: control (without product application); T1: Application $380 \mathrm{~g}$ ha-1 humic acid in the soil; T2; T3; T4: Application of humic acid foliar at doses of 380; 760; $1.520 \mathrm{~g} \mathrm{~L} \mathrm{h-1,} \mathrm{respectively.} \mathrm{In} \mathrm{experiment} \mathrm{2,} \mathrm{the} \mathrm{treatments} \mathrm{consisted} \mathrm{of} \mathrm{the} \mathrm{following}$ forms and fulvic acid application rates: control (without product application); T1: Application $200 \mathrm{~g}$ ha-1 humic acid in the soil; T2; T3; T4: Application of humic acid foliar at doses of 200; 400; $800 \mathrm{~g}$ $\mathrm{L}-1 \mathrm{~h}$. The application of humic acid in the seed furrows and foliar application at a dose of $380 \mathrm{~g}$ ha-1 in soybean V4 stage and the application of fulvic acid in the seed furrows promotes increased vegetative growth. In general the application of humic acid and fulvic acid in the seed furrows and foliar in V4 stage with a dose of $380 \mathrm{~g}$ ha-1 or $200 \mathrm{~g}$ ha-1, respectively, for humic and fulvic acid, increased the number of pods per plant, reflecting in grain yield increase.
\end{abstract}

Keywords: Soy, organic matter, humic acid, fulvic acid, leaf 


\section{INTRODUÇÃO}

Os solos arenosos apresentam como característica principal a baixa fertilidade, baixa retenção de água e capacidade de troca de cátions (CTC), em razão aos reduzidos teores de argila, dificultando o cultivo tanto de lavouras como de pastagens, sendo comuns as baixas produções de grãos e forragens. Neste sentido, a matéria orgânica (MO) é um dos fatores primordiais na manutenção da capacidade produtiva em solos arenosos. Os efeitos da $\mathrm{MO}$ estão relacionados com a higroscopicidade e à grande área superficial especifica deste material, o que promove o aumento da retenção de água (BRAIDA et al, 2011). Entretanto, em condições de clima tropical e em solos com baixos teores de argila, os desafios para o incremento do teor de MO são maiores, já que as temperaturas médias elevadas aumentam a atividade microbiana, e os baixos teores de argila reduzem a formação de agregados e limitam interação entre a fração orgânica e mineral do solo, deixando a MO exposta e vulnerável à degradação (FONTES et al., 2001; MENDONÇA et al., 2006).

Os ácidos húmicos e fúlvicos são responsáveis pela maior capacidade de troca catiônica (CTC) de origem orgânica nas camadas superficiais do solo, e pelos efeitos indiretos nas propriedades químicas, físicas e biológicas do solo onde estão concentrados os resíduos culturais (BENITES et al., 2003). Nesse contexto, em solos muitos intemperizados de baixa CTC, as substancias húmicas tem um papel importante no aporte nutricional e hídrico às plantas, pois aumenta o potencial de retenção de nutrientes nas camadas do solo que são explorados pelo sistema radicular das culturas anuais. As substâncias húmicas têm imensa capacidade de reter água no solo, mediante a formação de agregados. Pela propriedade coloidal das substâncias húmicas, a agregação das moléculas pelas ligações covalentes com o hidrogênio, formando estruturas esponjosas, com grandes espaços vazios, consegue reter grandes quantidades de água no solo, liberando-a lentamente para a planta, controlando sua água capilar (KIEHL, 1985; SILVA FILHO; SILVA, 2002). Kiehl (1985) cita que substâncias húmicas puras podem alcançar de 600 a 800\% de capacidade de reter água, ou seja, de 6 a 8 vezes o seu peso.

A degradação das substâncias húmicas no solo promove a liberação de compostos como $\mathrm{CO}_{2}, \mathrm{H}_{2} \mathrm{O}, \mathrm{NO}_{3}{ }^{-}, \mathrm{PO}_{4}{ }^{-2}, \mathrm{SO}_{4}{ }^{-2}$, etc., sendo uma importante fonte destes nutrientes para a biofauna do solo (SILVA FILHO; SILVA, 2002).Além dos efeitos indiretos, os ácidos húmicos podem promover efeitos estimuladores no crescimento de plantas na aceleração das taxas de crescimento radicular, incremento de biomassa vegetal, alterações na arquitetura do sistema radicular, tais como incremento da emissão de pelos radiculares e de raízes laterais finas, resultando no aumento na área superficial/comprimento do sistema radicular (NARDI, 1991; JUNIOR et al. 2008).

O trabalho teve o objetivo de avaliar a resposta da cultura da soja em razão da aplicação de ácidos fúlvicos e húmicos no sulco de semeadura e via foliar juntamente com herbicidas.

\section{MATERIAIS E MÉTODOS}

Os experimentos foram conduzidos na Fazenda Experimental da Universidade do Oeste Paulista - UNOESTE, em Presidente Bernardes-SP, com altitude média de 475 metros e o clima da região de Presidente Prudente-SP, segundo a classificação de Köppen, é do tipo Cwa, com temperaturas médias anuais em torno de 25 으 e regime pluvial caracterizado por dois períodos distintos, um chuvoso de outubro a março e outro de baixa precipitação pluvial de abril a setembro.Os dados climáticos registrados durante a condução do experimento estão contidos na 


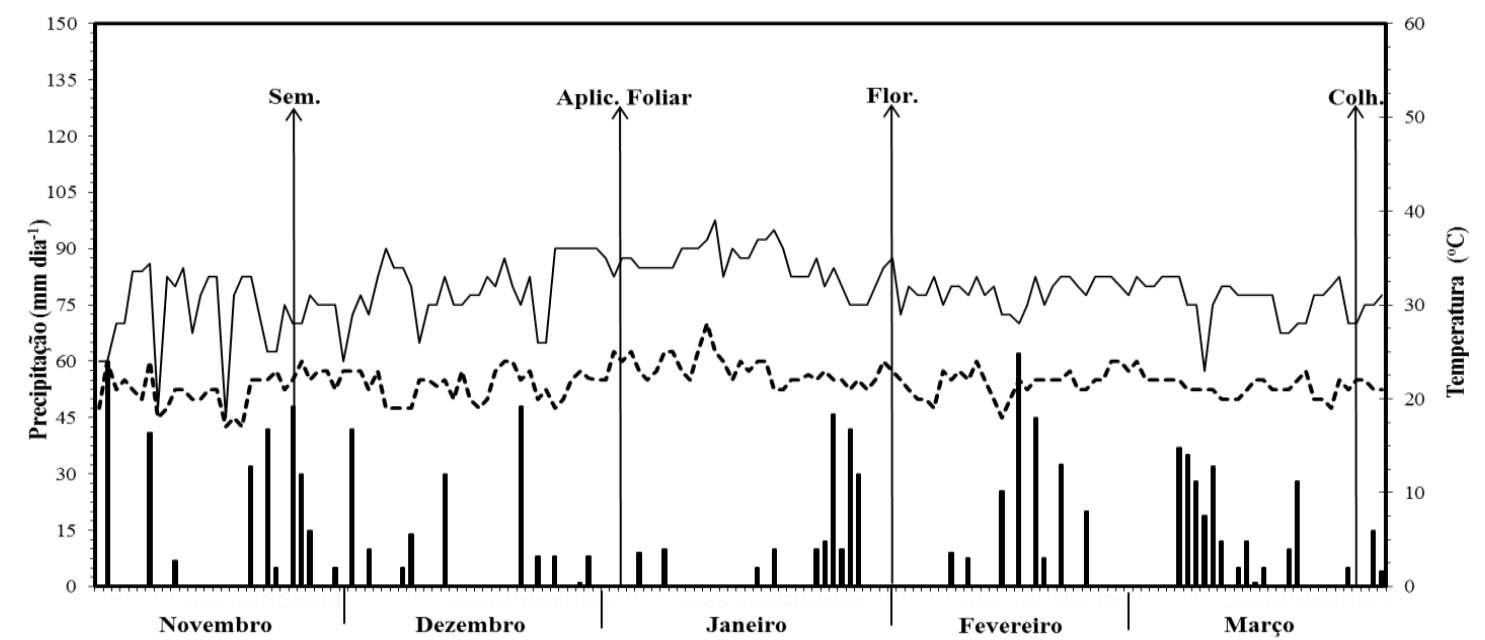

Figura 01. Precipitação pluvial (ا), temperatura máxima (-) e temperatura mínima (-) registradas na área experimental. Sem: semeadura da soja e aplicação dos produtos no sulco de semeadura (K-Humate e K-Fulvate); Aplic. Foliar: aplicação foliar dos produtos (glifosato + produto (K-Humate e K-Fulvate)); Flor: florescimento da soja; Colh: colheita da soja.

O solo da área experimental foi classificado como Argissolo Vermelho Amarelo distrófico de textura média-arenosa, de acordo com o Sistema Brasileiro de Classificação de Solos (EMBRAPA, 2006). Os resultados de análises químicas estão apresentados na Tabela 1.

Tabela 01. Características químicas do solo nas profundidades de 0-0,20 e 0,20-0,40 m, determinadas antes da instalação dos experimentos.

\begin{tabular}{|c|c|c|c|c|c|c|c|c|c|}
\hline Profundidade & $\mathrm{pH}\left(\mathrm{CaCl}_{2}\right)$ & M.O. & $\mathrm{P}$ (resina) & $\mathrm{H}+\mathrm{Al}$ & $\mathrm{K}^{+}$ & $\mathrm{Ca}^{2+}$ & $\mathrm{Mg}^{2+}$ & CTC & V \\
\hline $\mathrm{m}$ & & $g \mathrm{dm}^{-3}$ & $\mathrm{mg} \mathrm{dm} \mathrm{m}^{-3}$ & $\longrightarrow$ & & $\mathrm{mol}_{\mathrm{c}}$ & $n^{-3}$ & 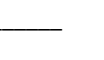 & $\%$ \\
\hline $0,0-0,20$ & 5,5 & 17,3 & 31,1 & 20,6 & 3,9 & 25,4 & 5,1 & 55,0 & 62,5 \\
\hline $0,20-0,40$ & 5,3 & 12,1 & 16,2 & 23,9 & 2,1 & 19,8 & 7,1 & 53,8 & 53,9 \\
\hline
\end{tabular}

Foi realizada a condução de dois experimentos, em ambos adotou-se o delineamento experimental em faixas, com quatro repetições. No experimento 1 e 2 foi realizado a aplicação de ácido húmico e ácido fúlvico, respectivamente. Como fonte de ácido húmico foi utilizado o produto comercial K-Humate ( $19 \%$ de ácido húmico, $3 \%$ de ácido fúlvico e $5 \%$ de $\mathrm{K}_{2} \mathrm{O}$ ), a fonte de ácido fúlvico foi utilizado o produto comercialK-Fulvate( $10 \%$ de ácido fúlvico e $2 \%$ de $\left.\mathrm{K}_{2} \mathrm{O}\right)$. No experimento 1 , os tratamentos foram constituídos pelas seguintes formase doses de aplicação de ácido húmico: Testemunha (sem aplicação de produto); T1: aplicação $380 \mathrm{~g} \mathrm{ha}^{-1}$ de ácido húmico via solo; T2; T3; T4: aplicação de ácido húmico via foliar nas doses de 380; 760; $1.520 \mathrm{~g} \mathrm{~L} \mathrm{ha}^{-1}$, respectivamente. No experimento 2 , os tratamentos foram constituídos pelas seguintes formas e doses de aplicação de ácido fúlvico: Testemunha (sem aplicação de produto); T1: aplicação $200 \mathrm{~g}$ ha ${ }^{-1}$ de ácido húmico via solo; T2; T3; T4: aplicação de ácido húmico via foliar nas doses de 200; 400; $800 \mathrm{~g} \mathrm{~L} \mathrm{ha}^{-1}$, respectivamente cada parcela foi demarcada com $6 \mathrm{~m}$ de largura por $30 \mathrm{~m}$ de comprimento, com uma área total de $180 \mathrm{~m}^{2}$. Foram semeadas quatorze fileiras de soja espaçadas em $0,45 \mathrm{~m}$. Para avaliação foram consideradas as quatro fileiras centrais da soja.

No dia 24/11/2014, foi realizada a semeadura da cultura da soja cv. BMX Potência RR em sistema de semeadura direta. As sementes foram tratadas com o fungicida carboxin + tiram $(60+$ $60 \mathrm{~g}$ do i.apôr $100 \mathrm{~kg}$ de sementes) e com o inseticida imidacloprido + Thiodicarb $(75$ + $135 \mathrm{~g}$ do i.a. por $100 \mathrm{~kg}$ de semente) com espaçamento entre fileiras de $0,45 \mathrm{~m}$, na adubação de semeadura foi aplicado o fertilizante formulado 08-28-16, na dose de $250 \mathrm{~kg} \mathrm{ha}^{-1}$. Simultaneamente a semeadura foi realizada a aplicação dotratamento pré-determinados (T1), misturado no tanque de 
aplicação juntamente com o inoculante. Quando as plantas estavam no estádio V4, foi realizada a adubação potássica de cobertura a lanço, na dose de $54 \mathrm{~kg} \mathrm{ha}^{-1}$ de $\mathrm{K}_{2} \mathrm{O}$, utilizando como fonte de cloreto de potássio.

Para o controle de plantas daninhas na cultura, foi aplicado glifosato $\left(1,4 \mathrm{~g} \mathrm{ha}^{-1}\right.$ do i.a. $\left.\mathrm{ha}^{-1}\right)$ no dia 02/01/2015, utilizando vazão de calda de $200 \mathrm{~L}$ ha ${ }^{-1}$. Juntamente com aplicação do herbicida foram aplicados os tratamentos pré-determinadas (T2; T3 e T4).

Por ocasião do florescimento pleno da cultura (28/01/2015), foram coletadas 10 plantas por unidade experimental, cortando-as rente à superfície do solo, em seguida foram submetidas à lavagem com água destiladas, posteriormente colocadas para secagem em estufa de ventilação forçada de ar a 65 ㅇ C por 72 horas, posteriormente pesadas para obtenção de matéria seca da parte aérea das plantas.

Quando a soja atingiu o ponto de colheitaforam determinaram-se os componentes da produção (população final de plantas, número de vagens por planta, número de grãos por vagem e massa de 100 grãos) em dez plantas de cada unidade experimental. Foram colhidas manualmente as plantas contidas em duas fileiras de $2 \mathrm{~m}$ de comprimento, na área útil de cada unidade experimental. Após a trilha mecânica e a limpeza, os grãos foram pesados e, posteriormente, foi calculada a produtividade de grãos, em $\mathrm{kg} \mathrm{ha}^{-1}$, a $13 \%$ de umidade (base úmida).

Os dados obtidos foram submetidos à análise de variância. As médias dos tratamentos foram comparadas pelo teste de Tukey a $5 \%$ de probabilidade.

\section{RESULTADOS E DISCUSSÃO}

Com relação à matéria seca da parte aérea das plantas de soja coletadas no florescimento (Figura 2), foi possível observar que a aplicação de ácido húmico e ácido fúlvico no sulco de semeadura (Tratamento: T1) e na aplicação via foliar na dose de $380 \mathrm{~g} \mathrm{ha}^{-1}$ de ácido húmico ou 200 $\mathrm{g}$ ha ${ }^{-1}$ de ácido fúlvico (Tratamento: T2), a matéria seca foi superior em relação á testemunha. $\mathrm{Na}$ aplicação de ácido fúlvicono sulco de semeadura (Tratamento: T1), este parâmetro foi superior aos demais tratamentos e à testemunha. Estas respostas podem estar relacionadas ao efeito direto dos ácidos orgânicos de alto peso molecular com os ácidos húmicos e fúlvicos no crescimento de plantas, aumento nas taxas de crescimento radicular, incremento de biomassa vegetal, alterações na arquitetura do sistema radicular, tais como incremento da emissão de pelos radiculares e de raízes laterais finas, resultando no aumento na área superficial/comprimento do sistema radicular (NARDI, 1991). De acordo com Vaughan et al. (1985) os efeitos das substâncias húmicas nas plantas estão relacionados com o aumento na absorção de nutrientes, devido à influência na permeabilidade da membrana celular e ao poder quelante, bem como à fotossíntese, à formação de ATP, aminoácidos e proteínas.

Os tratamentos estudados não influenciaram a população de plantas avaliadas por ocasião da colheita. Sendo que as populações de plantas médias observadas foram de 210.368 plantas ha' 1 , sendo abaixo da taxa de semeadura empregada (333.330 plantas ha ${ }^{-1}$ ) ocasionada pelas altas precipitações ocorridas após a semeadura (Figura 1), reduzindo a germinação das sementes. 


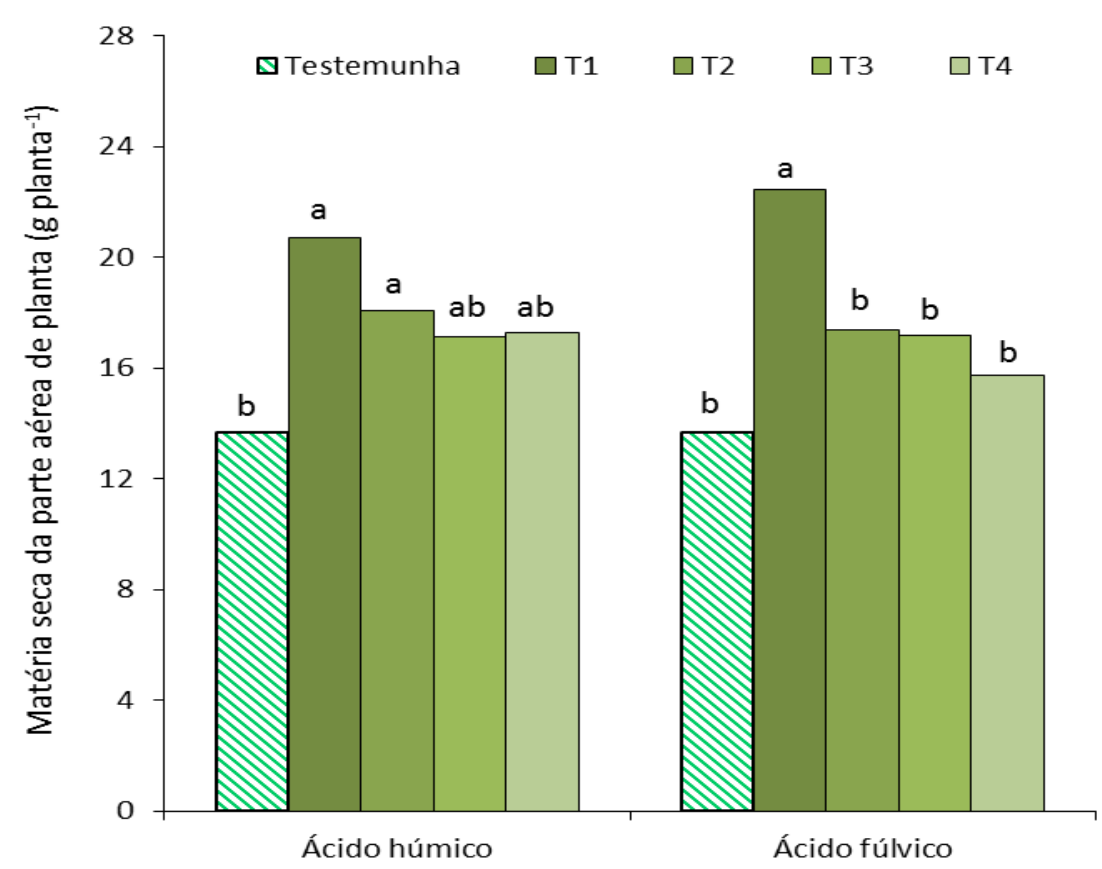

Figura 2. Matéria seca da parte aérea, em razão das formas de aplicação de ácido húmico ou ácido fúlvico. As barras com letras distintas diferem as formas de aplicação, pelo teste Tukey a 5\% probabilidade. Testemunha: sem aplicação; T1: aplicação $380 \mathrm{~g} \mathrm{ha}^{-1}$ de ácido húmico ou $200 \mathrm{~g} \mathrm{ha}^{-1}$ de ácido fúlvico via solo; T2; T3; T4: aplicação via foliar nas doses de 380; 760; $1.520 \mathrm{~g} \mathrm{~L} \mathrm{ha}^{-1}$ de ácido húmico ou 200; 400; $800 \mathrm{~g} \mathrm{~L} \mathrm{ha}^{-1}$ de ácido fúlvico, respectivamente.

Em geral a aplicação de ácido húmico e ácido fúlvico no sulco de semeadura e via foliar na dose de $200 \mathrm{~g} \mathrm{ha}^{-1}$ e no estádio V4, promoveu aumento do número de vagens por planta (Figura 2a). A aplicação de ácido húmico via foliar na dose de $1520 \mathrm{~L} \mathrm{ha}^{-1}$ no estádio V4, aumentou o número de grãos por vagens, já para a aplicação de ácido fúlvico não houve diferença estatística entre os tratamentos (Figura 2 b). 0 peso de 100 grãos não foi influenciado pelos tratamentos aplicados no preste experimento (Figura $2 \mathrm{c}$ ).

Com relação à produtividade de grãos, é possível observar que a aplicação de ácido húmico ou fúlvico no sulco de semeadura e via foliar na dose de $200 \mathrm{~g} \mathrm{~L} \mathrm{ha}^{-1}$ no estádio V4, aumentou a produtividade em relação a testemunha (Figura 6 d). Estas respostas de aumento de produtividade de grãos com a aplicação de ácidos orgânicos, independente da forma de aplicação, podem estar relacionadas com o efeito da aplicação dos produtos no desenvolvimento da parte aérea das plantas (Figura 2), que consequentemente aumentou o número de vagens por planta. Todavia, aplicação de ácido húmico ou ácido fúlvico, pode ter contribuído no maior aporte hídrico às plantas, em razão da propriedade coloidal das substâncias húmicas, a agregação das moléculas pelas ligações covalentes com o hidrogênio, formando estruturas esponjosas, com grandes espaços vazios, consegue reter grandes quantidades de água no solo, liberando-a lentamente para a planta, controlando sua água capilar (KIEHL, 1985). Kiehl (1985) cita que substâncias húmicas com sua capacidade de retenção de agua pode ser um benefício para déficits hídricos sendo uma opção para a ocorrência de veranicos. Em solos de textura média-arenosa similar do presente experimento, os baixos teores de matéria orgânica aliados aos baixos teores de argila e à estrutura desses solos, com grande volume de macroporos, determinam sua baixa retenção de água. Neste contexto destaca-se a importância dos ácidos orgânicos como o húmico e fúlvico no desenvolvimento da cultura. 

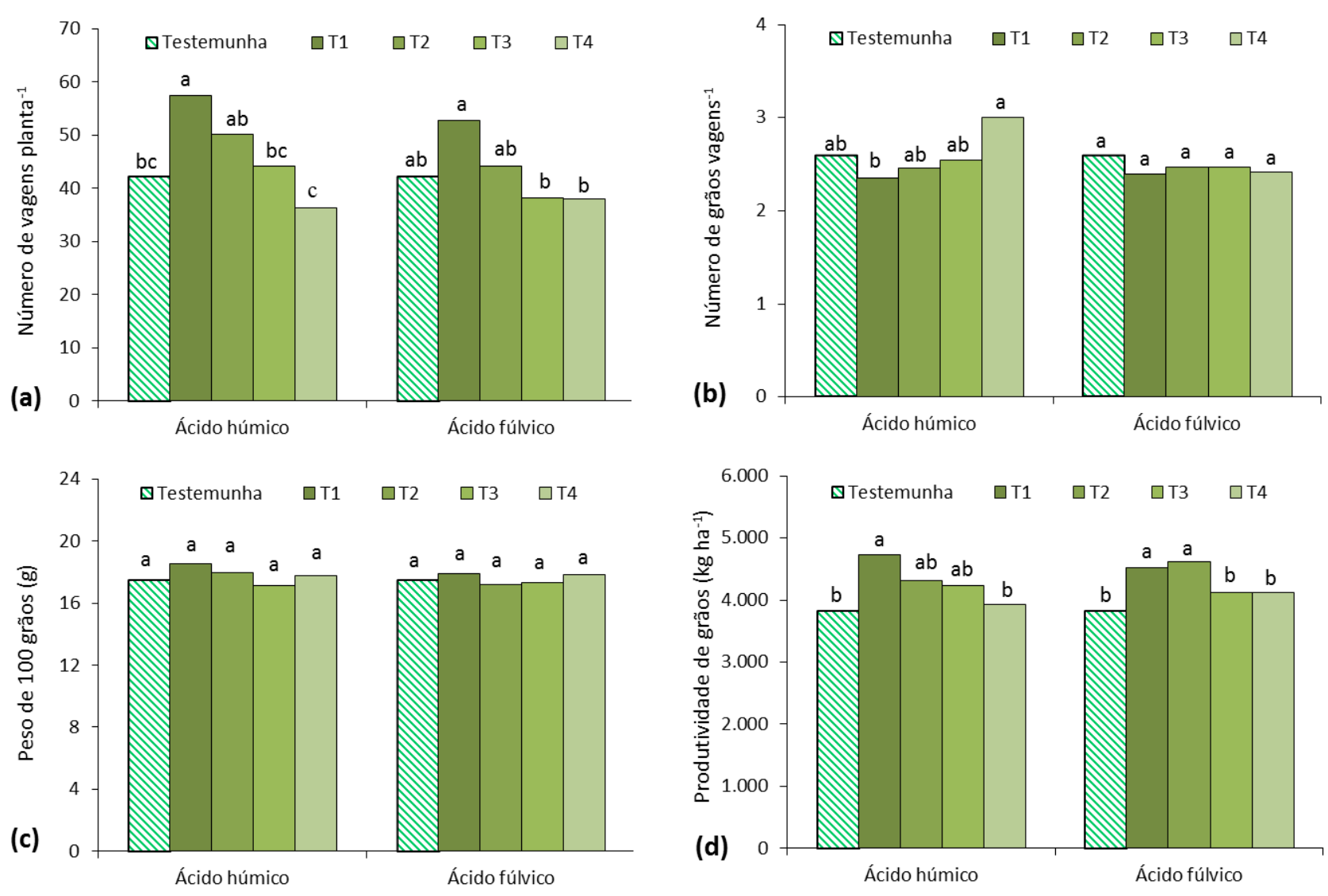

Figura 02. Número de vagens por planta (a), Número de grãos por vagens (b), Peso de 100 grãos (c) Produtividade de grãos (d), em razão das formas de aplicação de ácido húmico ou ácido fúlvico. As barras com letras distintas diferem as formas de aplicação, pelo teste Tukey a $5 \%$ probabilidade. Testemunha: sem aplicação; T1: aplicação $380 \mathrm{~g} \mathrm{ha}^{-1}$ de ácido húmico ou $200 \mathrm{~g}^{-1}$ de ácido fúlvico via solo; T2; T3; T4: aplicação via foliar nas doses de 380; 760; $1.520 \mathrm{~g} \mathrm{~L} \mathrm{ha}^{-1}$ de ácido húmico ou 200; 400; $800 \mathrm{~g} \mathrm{~L} \mathrm{ha}{ }^{-1}$ de ácido fúlvico, respectivamente.

\section{CONCLUSÃO}

No caso do ácido húmico a aplicação no sulco de semeadura e via foliar na dosagem de 380 g ha-1 no estágio V4 da cultura da soja promoveu aumento do crescimento vegetativo das plantas e aumentou do número de vagens por planta, repercutindo no aumento de produtividade de grãos.

A aplicação de ácido fúlvico no sulco de semeadura e via foliar no estádio V4 na dosagem de $200 \mathrm{~g}$ ha-1 promoveu aumento do crescimento vegetativo das plantas, e aumentou do número de vagens por planta, repercutindo no aumento de produtividade de grãos.

\section{REFERENCIAS}

BENITES, V.M.; MADARI, B.; MACHADO, P.L.O. A. Extração e fracionamento quantitativo de substâncias húmicas do solo: um procedimento simplificado de baixo custo. Rio de Janeiro: Embrapa Solos, 2003. 7p. (Comunicado Técnico, 16).

BRAIDA, J. A., BAYER, C., ALBUQUERQUE, J. A.; REICHERT, J. M. (2011). Matéria Orgânica e seu Efeito na Física do Solo. In: Klauberg Filho, O., Mafra, A. L. andGatiboni, L. C. Tópicos em Ciência do Solo. SBCS, v.7, p. 221-278. 
EMPRESA BRASILEIRA DE PESQUISA AGROPECUÁRIA. Centro Nacional de Pesquisa de Solos. Sistema brasileiro de classificação de solos. 2.ed. Rio de Janeiro: Embrapa Solos, 2006. 306p.

FONTES, M.P.F., CAMARGO, O.A.; SPOSITO, G. Eletroquímica das partículas coloidais e sua relação com a mineralogia de solos altamente intemperizados. Sci. Agric., v.58, p.627-646, 2001. https://doi.org/10.1590/S0103-90162001000300029

JUNIOR, R. B. M.; CANELLAS, L. P.; SILVA, L. G.da.; OLIVARES, F. L.; Promoção de enraizamento de microtoletes de cana-de-açúcar pelo uso conjunto de substâncias húmicas e bactérias Diazotróficasendofíticas. Revista Brasileira Ciências do Solo, v.32, p. 1121-1128, 2008. https://doi.org/10.1590/S0100-06832008000300020

MENDONÇA, E.S.; ROWELL, D.L.; MARTINS, A.G. SILVA, A.P. Effect of pH on the development of acidic sites in clayey and sandy loam Oxisol from the Cerrado Region, Brazil. Geoderma, v. 132, p.131-142, 2006. https://doi.org/10.1016/i.geoderma.2005.05.001

NARDI, S. et al. Nitrate uptake and ATPase activity in oat seedlings in the presence of twohumic fractions. Soil Biol\& Biochemistry, Amsterdam, v.23, n.9, p.833-836, 1991. https://doi.org/10.1016/0038-0717(91)90094-Z

KIEHL, E.J. FertilizantesOrgânicos. Ed. Agronômica Ceres, São Paulo, 492 p. 1985.

SILVA FILHO, A.V.; SILVA, M.I.V. Uso de ácidos orgânicos na agricultura. In:SEMINÁRIO DE NUTRIÇÃO VEGETAL, 1, 2002, Petrolina. Anais... Petrolina:Companhia de Agroquímicos, p.125-149, 2002.

STEVENSON, F.J. Humus Chemistry: Genesis, Composition, Reactions, second ed. John Wiley \& Sons, New York. 1994.

VAUGHAN, D.; MALCOM, R.E.; ORD, B.G. Influence of humic substances on biochemical processes in plants. In: VAUGHAN, D. \& MALCOM, R.E. Soil organic matter and biological activit. Dordrecht, Martinus Nijhoff/Junk W, 1985. p.77-108.https://doi.org/10.1007/978-94-009-5105-1 3 